\title{
Chick PTP $\sigma$ Regulates the Targeting of Retinal Axons within the Optic Tectum
}

\author{
Fiza Rashid-Doubell, lain McKinnell, A. Radu Aricescu, Gustavo Sajnani, and Andrew Stoker \\ Neural Development Unit, Institute of Child Health, London WC1N 1EH, United Kingdom
}

\begin{abstract}
Chick PTP $\sigma$ (cPTP $\sigma$ ), also known as $\operatorname{CRYP} \alpha$, is a receptor-like protein tyrosine phosphatase found on axons and growth cones. Putative ligands for CPTP $\sigma$ are distributed within basement membranes and on glial end feet of the retina, optic nerve, and optic tectum, suggesting that CPTP $\sigma$ signaling is occurring along the whole retinotectal pathway. We have shown previously that $\mathrm{CPTP} \sigma$ plays a role in supporting the retinal phase of axon outgrowth. Here we have now addressed the role of cPTP $\sigma$ within retinal axons as they undergo growth and topographic targeting in the optic tectum. With the use of retroviruses, a secretable cPTP $\sigma$ ectodomain was ectopically expressed in ovo in the developing chick optic tectum, with the aim of directly disrupting the function of endogenous CPTP $\sigma$. In ovo, the secreted ectodomains accumulated at tectal sites in which $\mathrm{CPTP} \sigma$ ligands are also specifically found, suggesting
\end{abstract}

The vertebrate retinotectal projection provides an excellent model in which to explore the molecular and cellular mechanisms of axon growth and topographic mapping (Thanos and Mey, 2001). These processes rely on the recognition by growth cones of environmental cues including cell adhesion molecules (CAMs), matrix molecules, and axon guidance molecules (for review, see Tessier Lavigne and Goodman, 1996; Chisholm and TessierLavigne, 1999). The functions of these cues can be broadly classified as being permissive and attractive to axons, or inhibitory and repulsive. Topographic mapping of axons requires the recognition and integration of both types of signal (Muller et al., 1996; Tessier Lavigne and Goodman, 1996; Dingwell et al., 2000).

The ephrin protein family and the repulsive guidance molecule are examples of repulsive cues in the optic tectum, inducing characteristic collapse of growth cones (Muller et al., 1996; Monschau et al., 1997; Frisen et al., 1998). With ephrins, these repulsive signals are transmitted through Eph receptor protein tyrosine kinases (RPTKs) (Drescher et al., 1995; O'Leary and Wilkinson, 1999). Our understanding of the signals that instead promote retinal axon growth within the optic tectum is more rudimentary. Maintenance of retinal axon growth in the retina

\footnotetext{
Received Aug. 20, 2001; revised March 18, 2002; accepted March 28, 2002.

This work was funded by the Wellcome Trust (Grant 046188), The Royal Society, European Commission Grant HPRN-CT-2000-00085 (G.S.) and studentships from the Medical Research Council, UK (I.M.) and University College London (A.R.A.). We thank Dieter Dütting for invaluable advice with the DiI tracing and Bruce Morgan for the gift of the viral gag plasmid. We are grateful to A. Copp and T. Doubell for critical reading of this manuscript.

Correspondence should be addressed to Andrew Stoker, Neural Development Unit, Institute of Child Health, 30 Guilford Street, London WC1N 1EH, UK. E-mail: Astoker@ich.ucl.ac.uk.

F. Rashid-Doubell's present address: Nuffield Department of Obstetrics and Gynecology, John Radcliffe Hospital, Oxford OX3 9DU, UK.

Copyright (C) 2002 Society for Neuroscience $\quad 0270-6474 / 02 / 225024-10 \$ 15.00 / 0$
}

that they are binding to these endogenous ligands. Anterograde labeling of retinal axons entering these optic tecta revealed abnormal axonal phenotypes. These included the premature stalling and arborization of fibers, excessive pretectal arbor formation, and diffuse termination zones. Most of the defects were rostral of the predicted termination zone, indicating that cPTP $\sigma$ function is necessary for sustaining the growth of retinal axons over the optic tectum and for directing axons to their correct sites of termination. This demonstrates that regulation of $\operatorname{cPTP} \sigma$ signaling in retinal axons is required for their topographic mapping, the first evidence of this function for a receptor-like protein tyrosine phosphatase in the retinotectal projection.

Key words: tyrosine phosphatase, PTP ; axon guidance; topographic; retina; optic tectum; Dil and optic nerve requires CAMs and integrins (Cohen et al., 1986; Chang et al., 1987; Neugebauer et al., 1988). It is less clear whether CAMs have a growth-promoting role on axons within the tectum (Thanos et al., 1984; Yin et al., 1995). In Xenopus, fibroblast growth factor (FGF) signaling through its receptors can promote axon entry into the tectum, but the role of FGF within the tectum is not certain (for review, see McFarlane et al., 1995; Dingwell et al., 2000). Therefore there remains a need to characterize molecules that encourage growth of axons over the tectum and to understand how these integrate with other guidance cues.

Of interest here are the receptor-like protein tyrosine phosphatases (RPTPs), a large family of proteins that are increasingly implicated in axon growth and guidance (Garrity et al., 1999; Bixby, 2000; Newsome et al., 2000; Stoker, 2001). The RPTPs РTP $\sigma, \operatorname{PTP} \delta$ and $\mathrm{PTP} \mu$ are expressed strongly in retinal ganglion cell axons (Stoker et al., 1995; Schaapveld et al., 1998; Ledig et al., 1999b; Johnson and Holt, 2000) and promote retinal neurite outgrowth (Burden-Gulley and Brady-Kalnay, 1999; Ledig et al., 1999a; Johnson et al., 2001) and growth cone steering (Sun et al., 2000 ) in culture. Moreover, Xenopus PTP $\delta$ supports axon growth in the optic tract in vivo. We reasoned that RPTPs might also promote retinal axon growth within the tectum and possibly influence topographic mapping. To address this, we have focused on the role of chick PTP $\sigma(\mathrm{cPTP} \sigma)$, formerly known as CRYP $\alpha$ (Stoker, 1994). cPTP $\sigma$ is located on retinal growth cones (Stoker et al., 1995), and its ligands are found in tectal basement membranes and the underlying stratum opticum (Haj et al., 1999; Aricescu et al., 2002). Using a strategy for perturbing cPTP $\sigma$ ectodomain function in ovo, we now show that $\mathrm{CPTP} \sigma$ is required for the growth and topographic targeting of retinal axons within the optic tectum. 


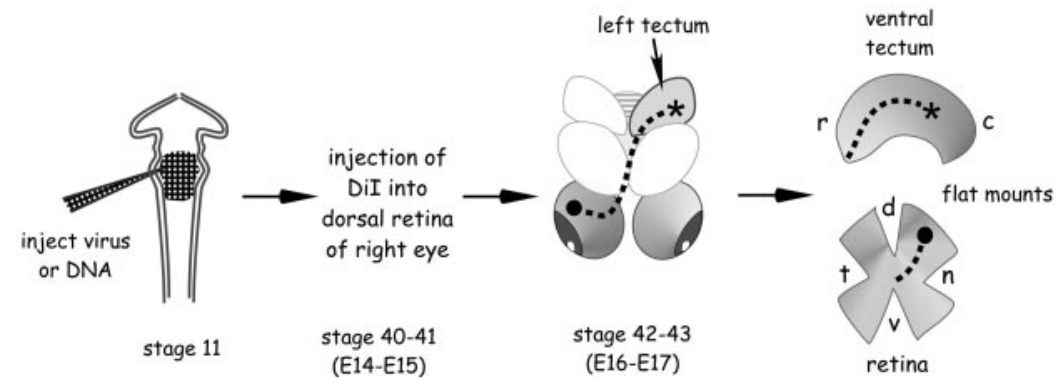

- DiI injection site
DiI-labelled axon track
* DiI-labelled
Figure 1. Schematic drawing of the virus infection and DiI injection procedure. Virus or viral DNA is injected into the mesencephalon at stage 11, and DNA is electroporated. DiI crystals are injected into the right eye at stage 40-41. Eyes and tecta are dissected out $2 \mathrm{~d}$ later, flat mounts are made, and the DiI trace (dashed lines) is recorded. Orientations are as follows: $r$, rostral; $c$, caudal; $d$, dorsal; $v$, ventral; $n$, nasal; $t$, temporal.

\section{MATERIALS AND METHODS}

Retroviral vectors. Secretable forms of the cPTP $\sigma 1$ ectodomain [formerly called the CRYP $\alpha 1$ isoform (Stoker, 1994)] were engineered into retroviruses. Oligonucleotides encoding either a myc or a vesicular stomatitis virus (vsv) glycoprotein epitope tag (Kreis, 1986) were inserted into a Hind III site of the cPTP $\sigma 1$ cDNA (bp 2269; GenBank accession code L32780) followed by stop codons. The modified PTP $\sigma$ ectodomain cassettes were cloned into the ClaI site of the RCASBP(A) retroviral vector (Hughes et al., 1987), producing vectors designated RCPTP $\sigma$. Both the myc- and vsv-tagged vectors behaved similarly in this work. The viral constructs were transfected into line zero chick embryo fibroblasts (Institute for Animal Health, Newbury) by either calcium phosphate transfection or Superfect (Qiagen Ltd., UK). Transfected cells were passaged four times over 7-14 d in DMEM medium with high glucose, $10 \%$ fetal bovine serum (FBS), $2 \%$ heat inactivated chick serum (CS), and 1\% penicillin/streptomycin. Virus was collected in DMEM, 1\% FBS, $0.2 \%$ CS and concentrated as described previously (Morgan and Fekete, 1996). Titers of $\sim 2 \times 10^{8}$ infectious units $/ \mathrm{ml}$ were obtained, comparable to those obtained with control viruses such as RCASAP (containing the human placental alkaline phosphatase cDNA) (Fekete and Cepko, 1993).

Immunoblotting. Chick embryo fibroblasts were infected with RCPTP $\sigma$ viruses as above, and supernatants were collected after $2-5 \mathrm{~d}$ of conditioning. These were centrif uged to clear debris, and $30 \mu \mathrm{l}$ were subjected to SDS-PAGE and semidry electroblotting onto polyvinylidene difluoride membranes (Stratagene, LaJolla, CA). Membranes were probed with antibodies to cPTP $\sigma$ [IG2 (Stoker et al., 1995), used at 1:2000 dilution] or the vsv epitope (P5D4, used at 1:2000; Sigma Aldrich) as described previously (Stoker et al., 1995). Primary antibodies were detected using horseradish peroxidase-linked anti-rabbit or anti-mouse secondary antibodies (Dako) diluted 1:2000. HRP was detected using ECL Plus (Amersham Biosciences).

Virus injection and electroporation. Fertile White Leghorn eggs (Needle Farm, Hertforshire, UK) were incubated at $38^{\circ} \mathrm{C}$ in a forced air, humidified incubator (Curfew Incubators) until they reached embryo stages 10-11 (Hamburger and Hamilton, 1992). Virus was injected into the mesencephalic lumen in ovo, using a drawn out glass microcapillary and PM1000 microinjector (Microdata Instruments Inc., Woodhaven, NY). Eggs were resealed with Scotch tape and reincubated. For electroporation, plasmid DNA containing the viral genome $(2 \mathrm{mg} / \mathrm{ml}$ in PBS, $1 \mathrm{~mm}$ $\mathrm{MgCl}_{2}$ ) was injected as above and then electroporated using a BTX 830 square wave generator (Genetronics, San Diego, CA) set at $20 \mathrm{~V}$, with five $50 \mathrm{msec}$ pulses at $0.95 \mathrm{sec}$ intervals. Eggs were resealed with tape and reincubated.

Axon labeling and analysis. The lipophilic dye 1,1'-dioctadecyl$3,3,3^{\prime}, 3^{\prime}$-tetramethylindocarbocyanine perchlorate (DiI) was used as an anterograde axonal marker (Honig and Hume, 1986) essentially as described in Dütting and Thanos (1995). Briefly, at either embryonic day (E) 14 or 15, infected eggs were reopened, and a small crystal of DiI (D3911; Molecular Probes, Eugene, OR) was placed into the dorsal retina by insertion into a small hole created with sharp forceps. Eggs were resealed with tape and incubated for a further 48-68 hr. The retinas and tecta of operated embryos were dissected out and fixed overnight in $4 \%$ paraformaldehyde in PBS at $4^{\circ} \mathrm{C}$. After $24 \mathrm{hr}$, the retinas were flat mounted in glycerol mountant $[2 \mathrm{gm} N$-propylgallate (Sigma Aldrich), $8 \mathrm{ml}$ PBS, $90 \mathrm{gm}$ glycerol] under glass coverslips. Tecta were cut along their midline using a microscalpel, and the dorsal (medial) and ventral (lateral) halves were mounted as above. In the initial experiments, camera lucida drawings were made of the DiI projections. In all other experiments, digital photomicrographs were taken using a Zeiss Axiophot and an Orca1 digital camera with OpenLab software (Improvision), and photomontages were constructed using Photoshop (Adobe).

In situ hybridization, histology, and immunohistochemistry. Infected E12 tecta were dissected and fixed in $4 \%$ paraformaldehyde in PBS overnight. Tissue was equilibrated in $30 \%$ sucrose in PBS and embedded in OCT compound (Sakura Finetek, Torrance, CA), and $10 \mu \mathrm{m}$ cryosections were cut. Neighboring sections were processed for either RNA in situ hybridization with the digoxigenin system (Roche Molecular Biochemicals, Hertforshire, UK), as described previously (Ledig et al., 1999a), or hematoxylin and eosin histology using standard techniques. The riboprobe was generated from the gag gene of Rous sarcoma virus and was a gift from Bruce Morgan (Harvard University, Boston, MA). For immunohistochemistry, tissue sections were made as above and were preblocked using a biotin blocking system (Dako Ltd.). Anti-vsv monoclonal P5D4 (Sigma) was added at 1:500 in antibody dilution buffer (Dako Ltd.). After washing, biotinylated anti-mouse reagent, streptavidin-linked HRP, and substrate were added sequentially according to manufacturers recommended protocols (Dako Ltd.).

\section{RESULTS}

\section{Generation of RCPTP $\sigma$ retroviruses}

A retroviral expression system was developed for the purpose of perturbing interactions between the ectodomain of axonal $\mathrm{PPTP} \sigma$ and the proteins with which it interacts in the optic tectum, in particular its ligands. Ligands of $\mathrm{cPTP} \sigma$ have been localized previously using receptor affinity probe in situ methods and are seen in the tectal outer basement membrane and in the underlying stratum opticum (Haj et al., 1999). Recently, one class of ligand has been identified as heparan sulfate proteoglycans (HSPGs) (Aricescu et al., 2002). The retroviral perturbation system was developed from a successful approach used in vitro, in which purified fusion proteins were used to mask retinal ligands of $\operatorname{cPTP} \sigma$ (Ledig et al., 1999a). In the current study, cDNA fragments encoding the ectodomain of the cPTP $\sigma 1$ isoform (Stoker, 1994) were first fused to C-terminal epitope tags. Fusion proteins with either myc or vsv epitope tags behaved similarly (see Materials and Methods). The cDNAs were then inserted into the RCASBP(A) retrovirus (Hughes et al., 1987), an established expression vector for use in ovo (Bell and Brickell, 1997). The vectors were designated RCPTP $\sigma$ and used alongside the control virus RCASAP, encoding human placental alkaline phosphatase (Fekete and Cepko, 1993).

The viral constructs were introduced into the mesencephalon at embryo stage 10-11, using either viral infection or electroporation of vector DNA (Fig. 1). These two methods gave rise to widespread patches of viral expression in the derived tecta, as detected with either whole-mount in situ hybridization or in situ 

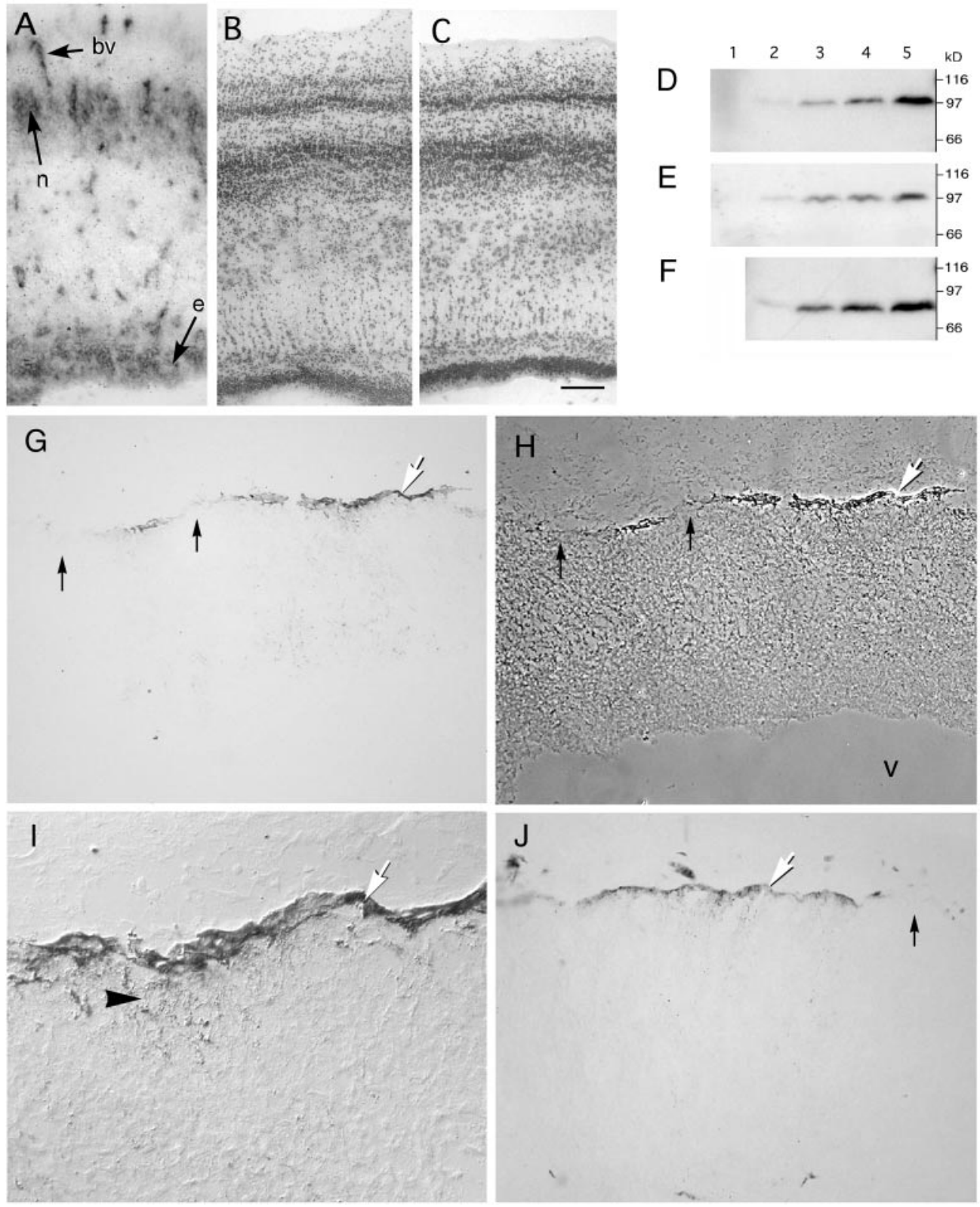

hybridization on tissue sections (Fig. 2A). At E12, midway through the topographic mapping process, infected tecta were examined histologically (Fig. $2 B$ ), and their laminated cytoarchitecture was found to be similar to that of both uninfected tissues (Fig. $2 C$ ) and tissue infected with control viruses (RCASAP; data not shown). Infected tecta grew normally to at least E17. During stages of topographic mapping, therefore, we saw no gross anatomical effects of RCPTP $\sigma$ infection.

The recombinant proteins encoded by RCPTP $\sigma$ vectors were readily detected in supernatants conditioned from infected fibroblast cultures (Fig. $2 D-F$ ). Protein levels were comparable to those used in a retinal perturbation system where they were effective at masking ligand interactions (Ledig et al., 1999a). In blot overlay and solid-phase binding assays, the same ectodomain proteins bound to $\mathrm{cPTP} \sigma$ ligands with high affinity (Aricescu et al., 2002). In infected tecta, the vsv-tagged fusion protein was seen in large patches over the tectal surface (Fig. $2 G-J$ ). In electroporated tecta, fusion protein was detected only in the electropo- rated, left hemisphere. The fusion protein was detected predominantly in the superficial basement membrane and its underlying stratum opticum (Fig. 2I). Significantly, this region also contains the highest levels of cPTP $\sigma$ ligands (Haj et al., 1999), including the recently described HSPG ligands (Aricescu et al., 2002). Thus the ectopic fusion protein accumulates specifically alongside its ligands, indicating that the two are very likely to be directly interacting in vivo. A similar colocalization of fusion protein with ligand is seen in infected retinas in vivo (Aricescu et al., 2002). When used to infect the optic tectum, therefore, the RCPTP $\sigma$ viruses will actively secrete cPTP $\sigma$ ectodomains that in turn should bind to, and at least partially mask, endogenous binding sites.

\section{Axonal projections in control tecta}

Anterograde DiI tracing was used to investigate the development of retinal axons within control and virus-infected optic tecta. DiI can label the entire length of retinal axons projecting to the tectum, and for a given DiI injection point in the dorsal retina the 

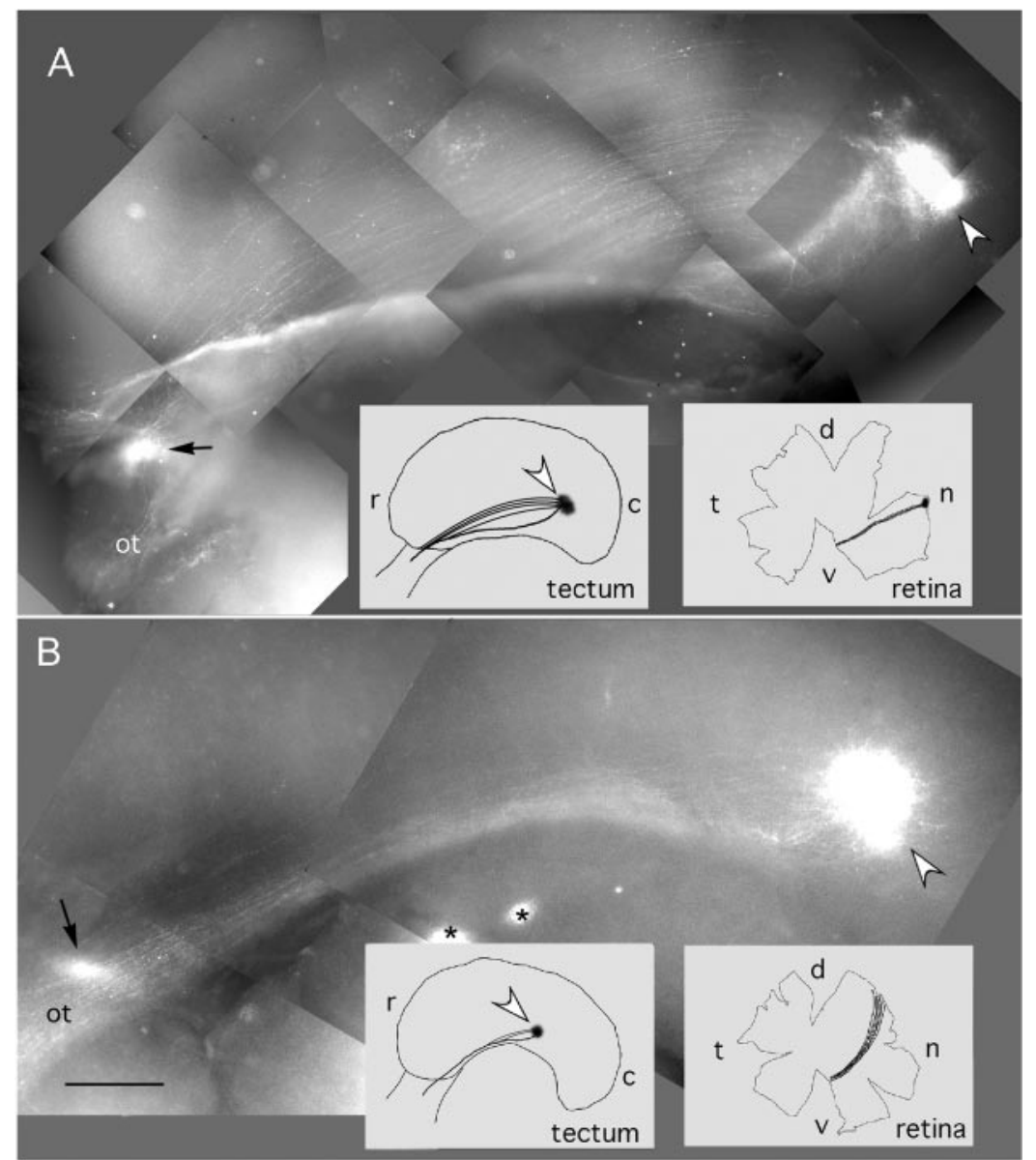

Figure 3. DiI projections in control embryos. $A$, Noninfected E17 tectum; $B$, E17 tectum electroporated at embryo stage 11 with control virus RCASAP. The main termination zones are labeled with white arrowheads. A simplified tracing of each projection in the tectum is shown to indicate the rostrocaudal location of the labeled projection, and tracings of the DiI track in each flat-mounted retina are shown. DiI-labeled pretectal nuclei are indicated by black arrows. Artifacts of fluorescence are indicated by asterisks. ot, Optic tract; $r$, rostral; $c$, caudal; $n$, nasal; $t$, temporal; $v$, ventral; $d$, dorsal. Scale bar, $0.25 \mathrm{~mm}$. arborization position in the ventral tectum can be predicted accurately (Nakamura and O'Leary, 1989; Dütting and Thanos, 1995; Ichijo, 1999; Yates et al., 2001). DiI crystals were inserted into the dorsal retina in ovo between E14 and E15, and eyes and tecta were fixed 2-3 d later (Fig. 1). All embryos had at least $2 \mathrm{~d}$ for DiI labeling of axons. The end point was therefore between E16 and E17, a stage when retinal axons should have formed terminal arbors and when both the initial overshooting of fibers and the ectopic collaterals characteristic of the immature projection should have been pruned back (Nakamura and O'Leary, 1989; Ichijo, 1999; Yates et al., 2001). Control projections were analyzed in uninfected embryos and in embryos infected with control virus RCASAP (Fekete and Cepko, 1993) (using both viral infection and electroporation). During each experiment, between 5 and $15 \%$ of embryos survived and had DiI projections for further analysis at E16-E17. Projections excluded from the analysis were those in which either multiple DiI traces or widely dispersed traces were observed in the retina, because their tectal projections are generally too complex to interpret with certainty. A range of nasal to temporal retinal axons were labeled, and their projections all terminated in their predicted, ventral tectal locations, characteristically arborizing in a single, compact zone similar to those described previously (Thanos and Bonhoeffer, 1987; Nakamura and O'Leary, 1989; Ichijo, 1999) (Fig. 3). In all cases the labeled fibers entered the main termination zone, and from 14 control embryos (from seven experiments), more than half had no stray axon projections (Table 1). In the remainder, projections had either (1) occasional fibers (one to three) that had overshot but not arborized beyond the main termination zone or (2) a
Table 1. Summary of DiI projection categories in control and RCPTPotreated embryos

\begin{tabular}{lccc}
$\begin{array}{l}\text { Experimental treat- } \\
\text { ment }\end{array}$ & $\begin{array}{l}\text { No pro- } \\
\text { jection } \\
\text { errors }\end{array}$ & $\begin{array}{l}\text { Minor } \\
\text { projection } \\
\text { errors }^{a}\end{array}$ & $\begin{array}{l}\text { Major } \\
\text { projection } \\
\text { errors }\end{array}$ \\
\hline $\begin{array}{l}\text { No virus treatment } \\
\text { RCASP-AP treated }\end{array}$ & 5 & 3 & 0 \\
RCPTP $\sigma$ treated & 5 & 1 & 0 \\
\end{tabular}

${ }^{a}$ Minor errors consist of small numbers of collateral branches rostral to the termination zone and/or overshooting fibers, as described in Results.

similar low frequency of collateral side branches in positions rostral to the main termination zone (data not shown).

On the basis of the known position of DiI crystal insertion, therefore, the DiI technique is a very good predictor of the tectal location of the termination zone. The data also demonstrate that control projections are robust, with few if any mislocated fiber terminals by E16-E17.

\section{Axon projection errors in RCPTP $\sigma$-infected tecta}

Given the baseline of normal axon terminations seen in control embryos, it is possible to define aberrant axonal projections in the chick tectum under appropriate experimental conditions (Hornberger et al., 1999). A full range of retinal projections were analyzed in RCPTP $\sigma$-infected tecta, from near the nasal midline (dorsally) to the temporal midline, and unless stated otherwise, the same exclusion criteria were used as for the controls. Aberrant projections to the brain were observed regardless of the initial DiI 

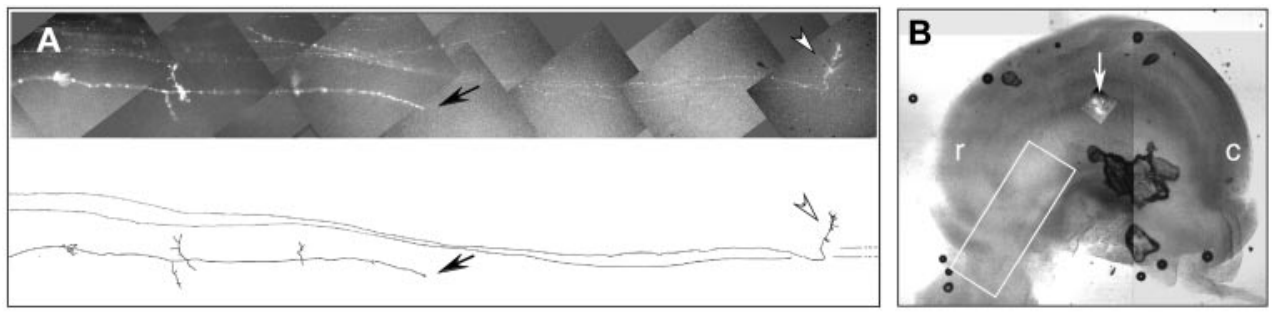

Figure 4. Premature terminations in RCPTP $\sigma$-treated tecta. Three axon projections are shown with fibers that have stalled or arborized, or both, at ectopic sites rostral to the main termination zones. $A, C$, and $E$ are photomontages of projections with computer-aided tracings shown alongside. $B, D$, and $F$ show lowmagnification views of each tectum with the regions in $A, C$, and $E$ boxed in white, and the main termination zones (at predicted locations) superimposed and indicated with white arrows. In $A$, black arrowheads indicate a blunt ending fiber remaining on the tectal surface. In $A, C$, and $E$, white arrowheads indicate fibers that have penetrated the tectum and undergone at least partial arborization. $A$ represents embryo 4 in Figure 8; $C$ represents embryo 9; $E$ represents embryo 11. $r$, Rostral; $c$, caudal. Scale bar, $2 \mathrm{~mm}$.
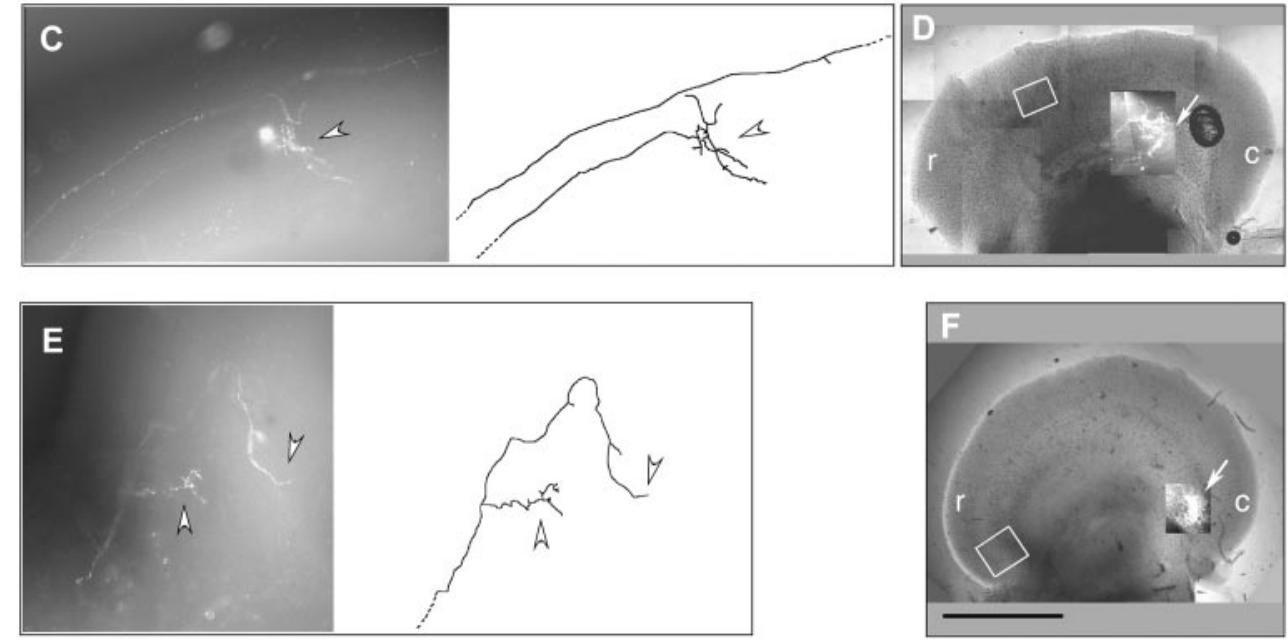

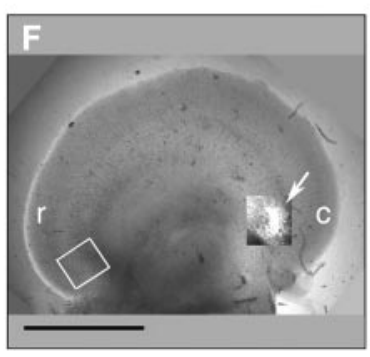

injection site and after either embryo infection or electroporation. One-third of labeled traces showed major projection errors (13 of 39) (Table 1). In the remaining tecta, the projections were either normal or had the kinds of minor stray fibers observed with control embryos (Table 1). Compared with the controls, the slightly higher frequency of minor errors in RCPTP $\sigma$-infected embryos was not statistically significant.

The abnormal phenotypes varied in severity. They were also usually partially penetrant, given that most projections contained a mixture of abnormal axons and axons that terminated in the correct (predicted) position. The abnormal phenotypes fell into several groups, all of which suggest that axons failed to grow a sufficient distance to their targets and misinterpreted topographic information within the tectum.

\section{Axons stop short of the target}

In more than half of the abnormal axonal projections (8 of 13), fibers were found to have stopped rostral to their target. These were either blunt-ended processes on the tectal surface (Fig. $4 A$, black arrow) or processes that had invaded the tectum with or without further arborization (Fig. 4A,C,E, white arrowheads). It is clear in these cases that fibers had not reached their target, because the main termination zones were evident (Fig. $4 B, D, F$, white arrows). There was no obvious pattern in the location of these aberrantly terminated fibers except that they all, except one (see below), terminated in the rostral half of the tectum.

\section{Excessive pretectal termination of axons}

In 3 of the 13 abnormal projections, DiI accumulated at disproportionately high levels in the optic tract and within pretectal nuclei, relative to the DiI present in fibers within the tectum. In one example, two termination zones were seen in the tectum as predicted from two close dorsotemporal DiI traces in the retina (Fig. 5A). Although such a double trace would normally have been excluded from the analysis, this exception was included because there was an obvious abnormality in DiI distribution. The tectal arbors were small, whereas most of the DiI label was in the tract, within pretectal nuclei, a phenotype not seen in control projections. In a second example, the projection totally failed to reach the tectal target (Fig. $5 B$ ). Only two fibers entered the tectum (black arrow in camera lucida drawing), but these stopped $50 \%$ of the distance to the predicted target (asterisk). The remaining DiI label had accumulated in pretectal nuclei or in fibers that stopped at or near the tectal border.

\section{Dorsoventral errors}

In three tecta, axons traveled aberrantly into the dorsal tectum. In one case an axon had traveled circuitously around the dorsal tectal perimeter before reaching a ventral termination site (Fig. $6 A$, white arrowhead). In this same tectum, a fiber fascicle made an unusual $90^{\circ}$ turn dorsally when it was half way to its target (Fig. $6 A$, bottom tracing, gray arrow) and then corrected itself before its two fibers terminated prematurely (black arrowheads). In two further tecta, one to two fibers entered the dorsal tectal rim where they stalled soon afterward (data not shown). In these three tecta the abnormalities can be viewed as possible errors in the dorsoventral guidance of retinal axons.

\section{Poor convergence on the termination zone}

In three abnormal projections, the predicted target zones contained axon terminals, but many other axons were meandering and dispersed over a larger area and had not converged as a normal, compact arborization. The projection in Figure $6 \mathrm{~A}$ comes from a very compact retinal DiI track (Fig. 6B), and we expected a similarly compact termination zone in the tectum. Instead, the region of fiber terminations is spread over $25 \%$ of the anteroposterior axis of the tectum at E17 (Fig. 6A). In a second example (Fig. $6 C$ ), only three discernible fibers had entered the tectum (of 18 that were labeled in the retinal DiI trace), and there was a poorly defined termination zone with wandering fiber 
A
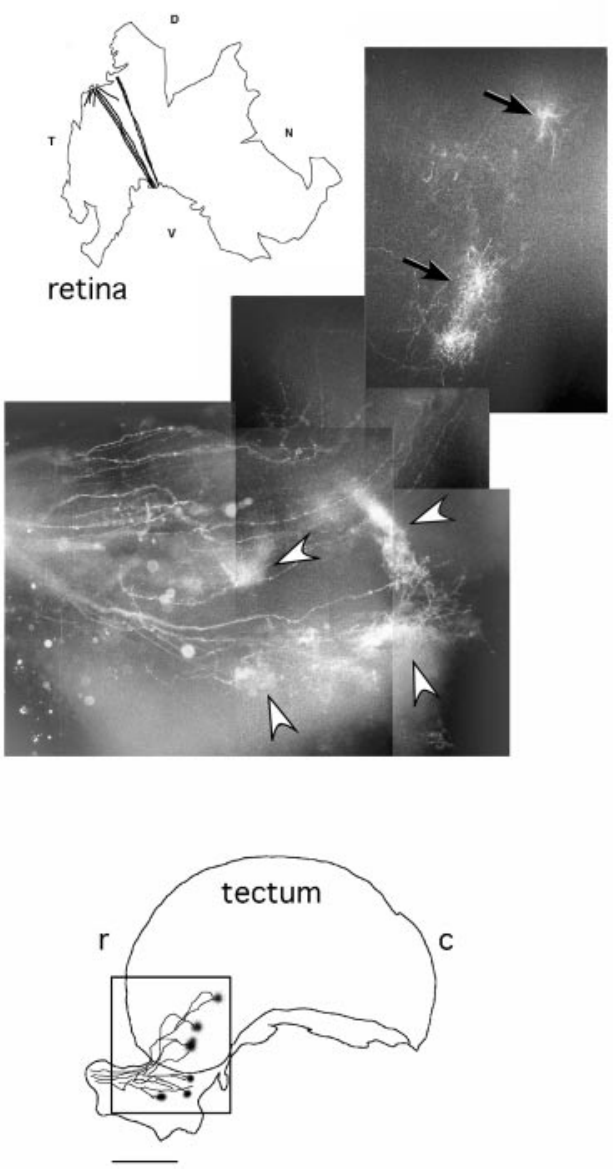

B
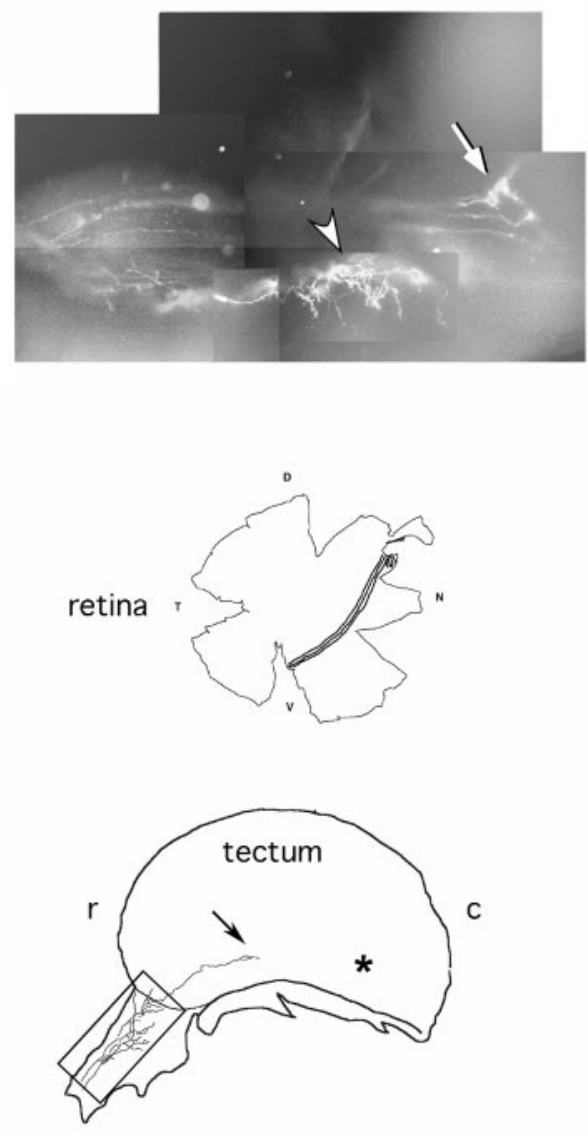

Figure 5. Disproportionate axonal labeling in pretectal nuclei in RCPTP $\sigma$-treated tecta. $A$, A projection that has two dorsotemporal retinal traces giving rise to two small termination zones in predicted locations (black arrows); most of the DiI label is outside the tectum and within pretectal nuclei (white arrowheads); this is embryo 1 of Figure 8. B, A dorsonasal projection in which nearly all DiI label is within a pretectal nucleus (white arrowhead) and in fibers stalled at the tectal border (white arrow); two fibers (black arrow) enter the tectum but fail to reach the predicted termination site ( $B$, asterisk); this is embryo 10 of Figure 8 . Retinal tracings of projections $A$ and $B$ are shown, as well as camera lucida tracings of their respective tectal projections. Boxes on the camera lucida tracings demarcate the photomicrograph composites shown above. $r$, Rostral; $c$, caudal; $n$, nasal; $t$, temporal; $v$, ventral; $d$, dorsal. Scale bar, $1 \mathrm{~mm}$ (for camera lucida tracings of tecta). terminals (Fig. 6C, black arrowhead). These errors suggest that retinal axons entering certain RCPTP $\sigma$-infected tecta do not accurately detect their correct targeting position even when these axons are broadly within reach of it.

\section{Abnormal formation of collaterals}

Another phenotypic abnormality was that of multiple rostral arborizations arising from collaterals. Axonal collaterals outside of the main termination zone are common in immature projections but are predominantly pruned away by E16 (Thanos and Bonhoeffer, 1987; Nakamura and O'Leary, 1989; Ichijo, 1999). As described above, occasional stray fibers can sometimes persist in control embryos. The projection in Figure $6 C$, however, had an abnormally high level of ectopic arbors, mostly derived from collaterals in the rostral quarter of the tectum (Fig. 6C, small black arrows) far from their target. Approximately $50 \%$ of the DiI label in the tectum was in this rostral region. In a second example (Fig. 7), a mass of small arbors (black arrowheads) was observed rostral to the termination zone, most of which again were collateral derived.

\section{Summary}

Figure 8 summarizes the abnormalities seen in 13 tecta, arising in temporal to nasal retinal projections. All of the defects, except the one apparent caudal termination in tectum 9, were rostral to the predicted termination zones, indicating that $\mathrm{cPTP} \sigma$ function is normally required for full extension of axons to their targets and selection of appropriate anteroposterior termination position. In addition, several experimental tecta contained multiple projec- tion errors. Tectum 9 (Fig. $6 A$ ) had a diffuse termination zone, stalled fibers (shown also in Fig. $4 C$ ), a mediodorsal $90^{\circ}$ turn, a caudal termination, and a fiber that traveled around the dorsal tectal rim. In tectum 7 (Fig. $6 C$ ), the projection had a poorly focused termination zone, a predominance of rostral arborizations, a stalled fiber, and disproportionate DiI label in pretectal nuclei. The perturbation strategy thus results in complex changes in the behavior of retinal growth cones, with multiple errors in anteroposterior and dorsoventral axes.

\section{DISCUSSION}

Using a specific approach for perturbing RPTP ectodomain function in ovo, we have provided the first evidence of RPTP function in retinal axons within the optic tectum. Our data reveal that cPTP $\sigma$ function is necessary for sustaining the onward growth of retinal axons as they invade the optic tectum. cPTP $\sigma$ also assists, either directly or indirectly, in targeting these axons to their correct arborization sites, in particular within the anteroposterior axis.

RPTPs have roles in promoting the outgrowth of retinal neurites grown under conditions mimicking the retinal environment (Burden-Gulley and Brady-Kalnay, 1999; Ledig et al., 1999a; Johnson et al., 2001). However, the roles of these RPTPs at later stages of retinotectal development, during intratectal growth and topographic mapping, have not been examined closely. The stratum opticum and the limiting basal lamina of the optic tectum are enriched for $\mathrm{CPTP} \sigma$ ligands during retinal axon invasion (Haj et al., 1999; Aricescu et al., 2002). We have used a novel perturbation approach in ovo to address the functional interactions be- 
Figure 6. Diffuse termination zones and multiple projection errors in RCPTP $\sigma$ treated tecta. $A$, A nasodorsal projection in which most fibers have gathered near the predicted termination zone ( $A$, asterisk) but have failed to form a compact arborization; this is embryo 9 of Figure 8. The photomontage of the ventral tectum and its tracing indicate four further abnormalities: a fascicle undergoing a $90^{\circ}$ dorsal turn ( gray arrow), a fiber stall/ectopic arbor (black arrowheads), a caudal arborization zone (black arrow), a stray fiber entering the ventral tectum having traveled around the dorsal tectum (white arrowhead). $B$, Traced DiI track in the flatmounted retina and a close-up of the track. $C$, A dorsal retinal projection and its tracing are shown; this is embryo 7 of Figure 8. Three abnormalities are indicated in $C$ : sparse, poorly focused main termination zone (black arrowhead), abnormal numbers of rostral, ectopic arbors (small arrows), and a stalled fiber (large black arrow). D, Tracings of the retinal DiI track and a lower magnification tracing of the tectum. $r$, Rostral; $c$, caudal; $n$, nasal; $t$, temporal; $v$, ventral; $d$, dorsal. Scale bars: $A$, $B, 0.2 \mathrm{~mm} ; C, 0.5 \mathrm{~mm}$.

\section{A}

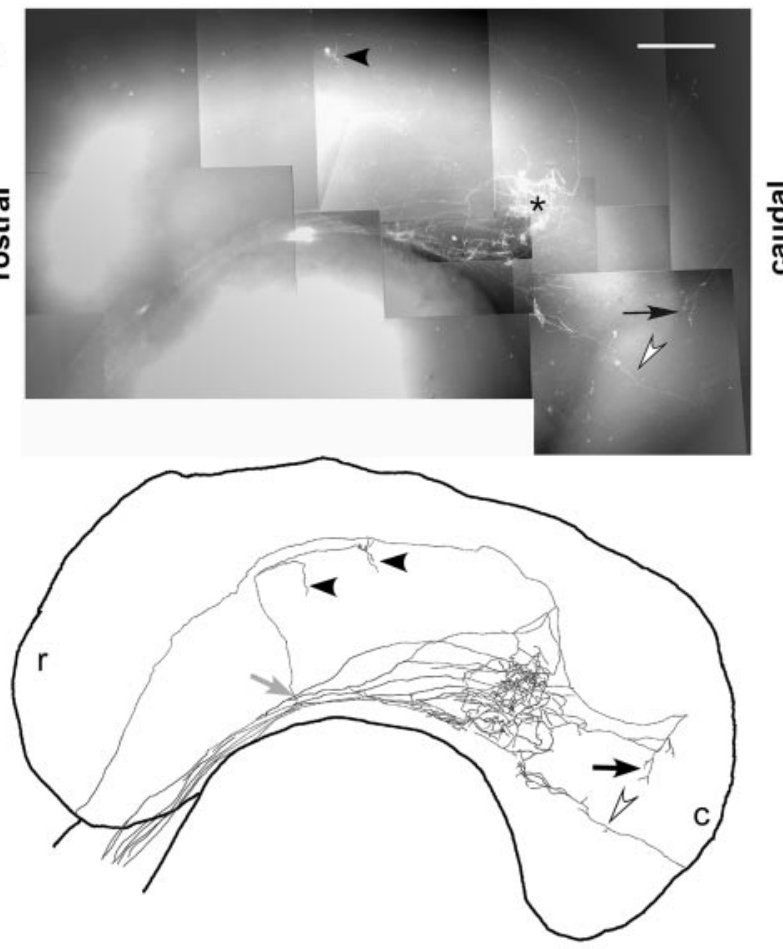

B
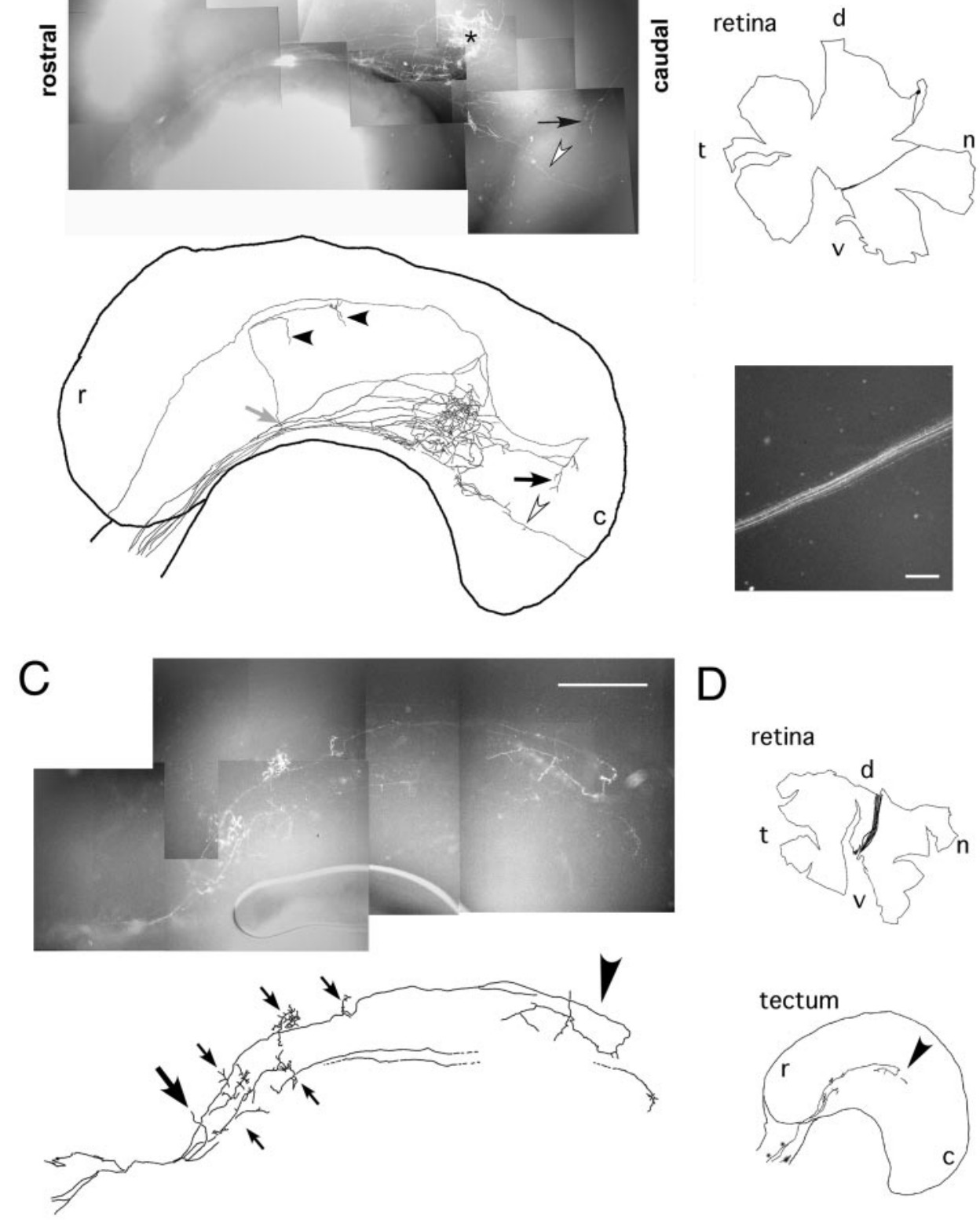

tween these ligands and cР TP $\sigma$. The approach resulted in abnormal axonal phenotypes, the majority of which were characterized as failure of fibers to establish arbors at their predicted targets. Such axons stopped en route to their targets, either with or without forming ectopic arbors. Other phenotypes included an apparent inability of axons to home in locally on their target zones and the presence of excessive, arborized collaterals on axons. In the collateral phenotype, either preformed ectopic collaterals have been selectively retained and not pruned or new collaterals may have formed in response to local $\mathrm{cPTP} \sigma$ perturbation. We cannot distinguish between these possibilities at present. We also noted that axons could be misrouted into the dorsal tectum or could undergo abnormal, dorsal turns before stalling. cPTP $\sigma$ signals may therefore also influence dorsoventral positioning of retinal axons. We propose that the collective pro- jection errors most likely result directly from reduced PTP $\sigma$ / ligand interactions, and we suggest therefore that PTP $\sigma$ signaling plays an essential part in controlling axon termination in the tectum.

The mechanisms by which ligands affect RPTP signaling are currently a subject of debate (Petrone and Sap, 2000). Although our experimental approach does not tell us directly how this signaling is working in the tectum, the data can be interpreted in several distinct ways that can be tested further. It is known that cPTP $\sigma /$ ligand interactions promote axon elongation in culture (Ledig et al., 1999a) and that the homophilic interactions of RPTPs such as $\mathrm{PTP} \mu, \mathrm{PTP} \kappa$, and $\mathrm{PTP} \delta$ also promote neurite outgrowth (Burden-Gulley and Brady-Kalnay, 1999; Drosopoulos et al., 1999; Wang and Bixby, 1999). Therefore the liganddependent signals from cPTP $\sigma$ may support axon growth over the 


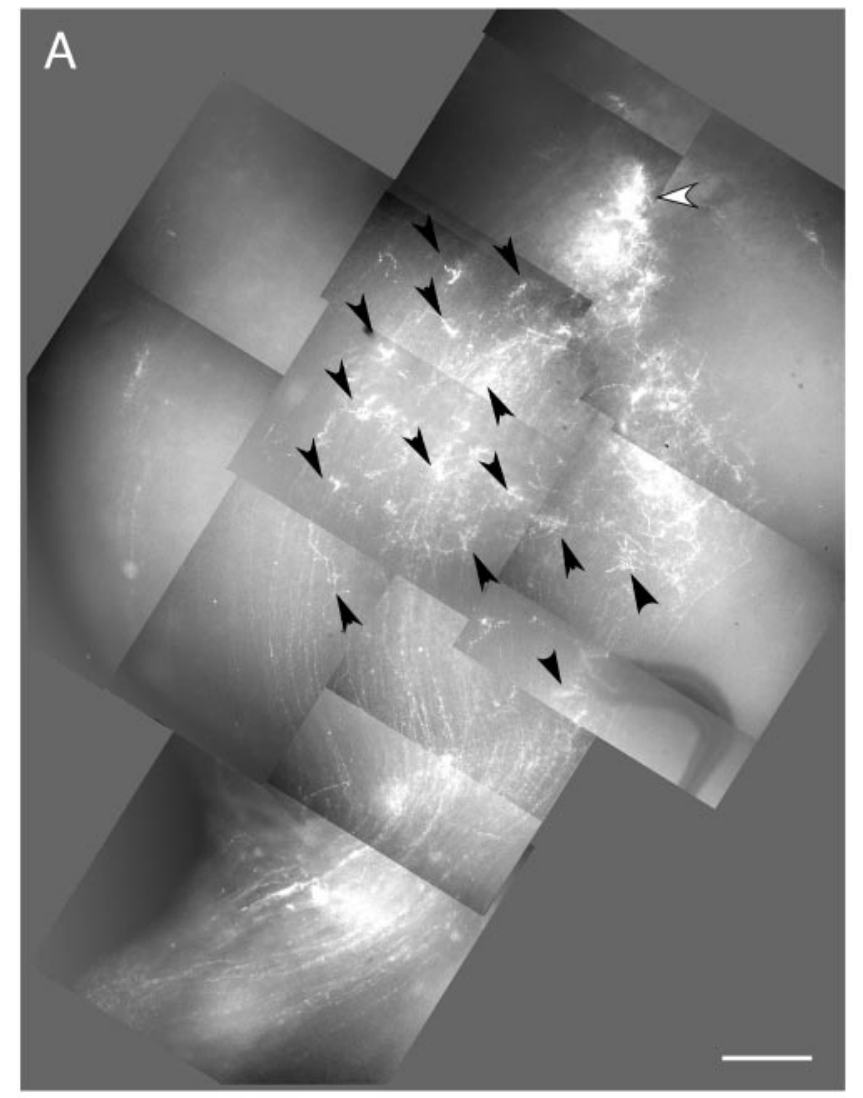

B
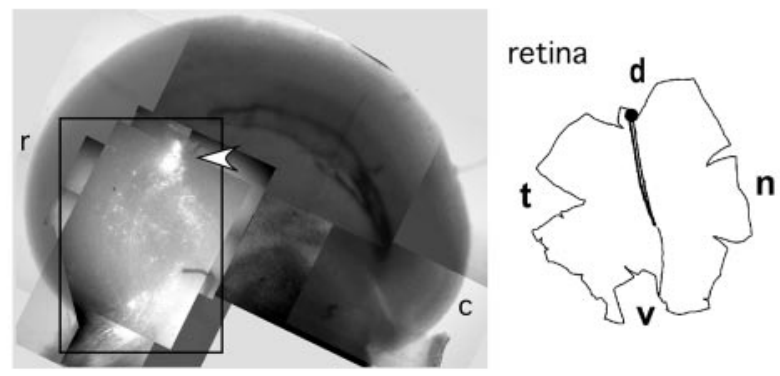

Figure 7. Excess, rostral collaterals and arbors in an RCPTP $\sigma$-treated tectum; this is embryo 2 of Figure $8 . A$, E17 ventral tectum showing a projection from the dorsal retina. The site of the predicted termination zone is indicated (white arrowhead). Rostral to this, large numbers of collaterals and associated arborizations are present (black arrowheads). $B$, Low-power view of the whole tectum (with boxed area as shown in $A$ ) and the respective, flat-mounted retina tracing. $r$, Rostral; $c$, caudal; $n$, nasal; $t$, temporal; $v$, ventral; $d$, dorsal. Scale bar, $0.2 \mathrm{~mm}$.

tectum while directly counterbalancing signals from chemorepulsive cues. Thus, at a given tectal position for each growth cone or collateral, RPTP signals and chemorepulsive signals might normally reach a balance, thereby initiating arborization. In this way, RPTPs could set a threshold of sensitivity to repulsive cues. If RPTP signals are blocked, for example in our current experiments, an increased sensitivity to chemorepulsive signals would ensue, and axons would prematurely invade rostral sites normally occupied by more temporal retinal axons. Although Eph RPTKs would make natural antagonistic partners for RPTPs in this scenario, there is no direct evidence for this currently. Nevertheless, this remains worthy of investigation given that antagonistic interactions occur between RPTPs and RPTKs in other vertebrate and invertebrate signaling systems (Ahmad and Goldstein,
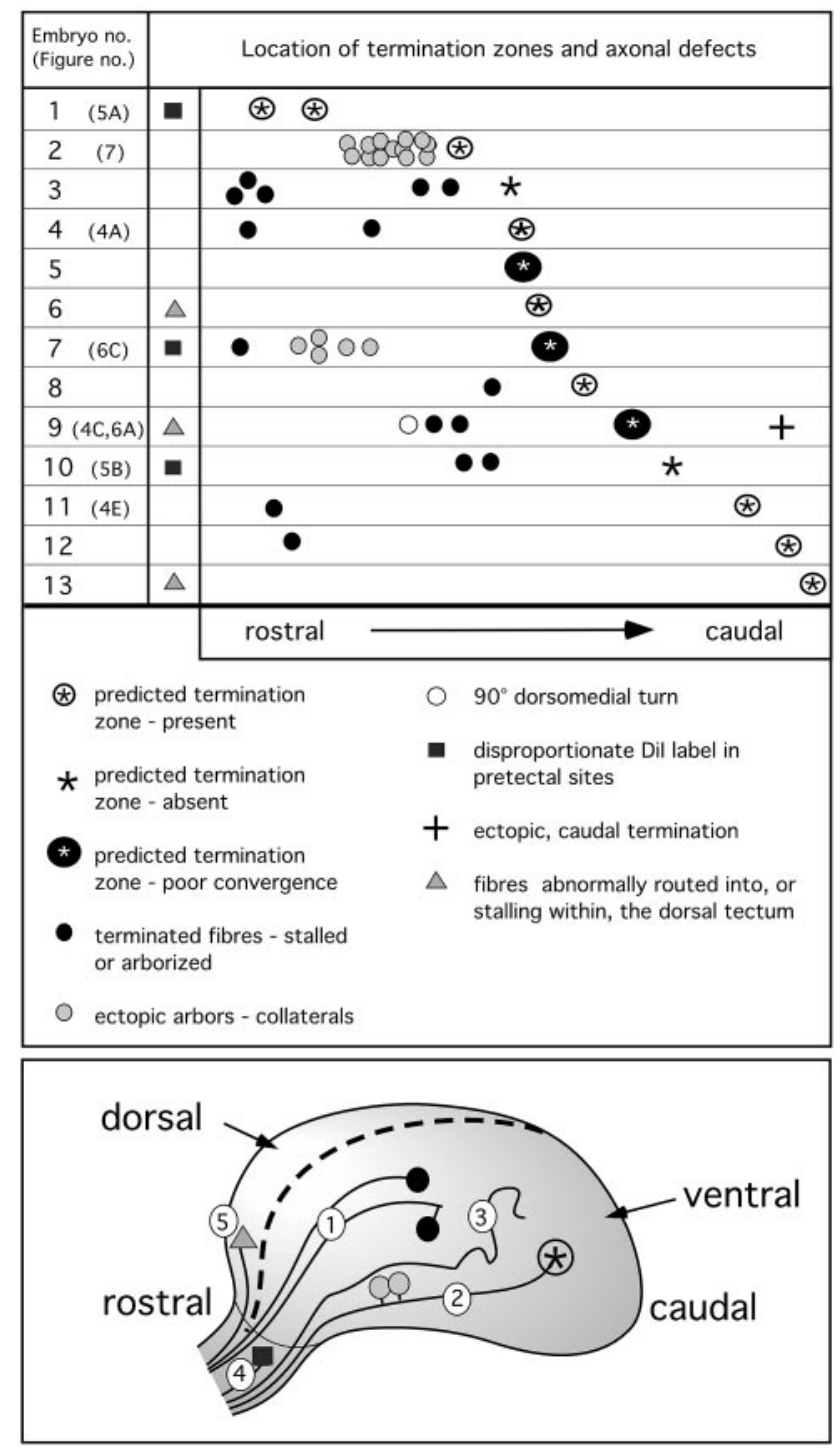

Figure 8. Summary of axonal phenotypes. Top panel, Each tectum is numbered, and the Figure number is indicated where relevant. The type and position of the projection errors in the rostrocaudal axis of the ventral tectum are depicted with the symbols indicated. Bottom panel, Schematic diagram depicting the errors shown in the top panel: (1) premature terminations and arborizations, (2) excessive, rostral collaterals, (3) poor convergence of fibers on predicted target zone, (4) disproportionate DiI label in pretectal regions, and (5) abnormalities in dorsal routing. The tectal midline is indicated with a dashed line.

1997; Kokel et al., 1998; Suarez Pestana et al., 1999; Ostman and Boehmer, 2001).

There is a second, perhaps less intuitive model to explain the axonal phenotypes. Biochemical signals from $\mathrm{cPTP} \sigma$ may not be activated but may instead be suppressed by the ligand. Here the role of the ligand would be to suppress $\mathrm{cPTP} \sigma$ signals that would otherwise act negatively on growth cone advance. Thus the ligand masking strategy would turn on $\mathrm{PTP} \sigma$ signaling at abnormal tectal sites, leading to stalling and premature arborizations. This could be viewed as a gain-of-function phenotype. In support of this model, several studies have shown that ligands potentially turn off RPTP catalysis (Desai et al., 1993; Bilwes et al., 1996; Jiang et al., 1999; Meng et al., 2000). Furthermore, putative dominant-negative mutations in Xenopus CRYP $\alpha$ (ortholog of 
сPTP $\sigma)$ increase neurite outgrowth on retinal substrates in vitro (Johnson et al., 2001). These findings, in combination with our previous study (Ledig et al., 1999a), are consistent with ligands suppressing cPTP $\sigma$ signaling to maintain retinal axon growth (Johnson et al., 2001). Given that $\mathrm{cPTP} \sigma$ perturbation leads to ectopic arborizations, there is also the intriguing possibility that cPTP $\sigma$ activation might be part of the trigger for arborization at the correct targets. This model is awkward to envisage, however, because $\mathrm{cPTP} \sigma$ is uniformly expressed in retinal ganglion cells (Ledig et al., 1999b), and the currently identified ligands are also apparently uniformly arrayed over the tectal surface (Haj et al., 1999; Aricescu et al., 2002). This requires us to invoke a further mechanism whereby the ligand for cPTP $\sigma$ is locally blocked in its action on the phosphatase (at arborization sites, for example). How might this occur? One possibility is that cPTP $\sigma$ is proteolytically cleaved in a topographically regulated manner, shedding its ectodomain to release it from ligand influences. cPTP $\sigma$ and other type 2 RPTPs are known to undergo such cleavage, at least in culture (SerraPages et al., 1994; Stoker et al., 1995), and this may trigger activation of the remaining phosphatase domains (Aicher et al., 1997).

A third explanation for the axonal phenotypes can also be envisaged, on the basis of our previous demonstration that cPTP $\sigma$ ectodomains bind to retinal fibers themselves (Haj et al., 1999). Such axonal binding sites could act as "receptors," with $\operatorname{cPTP} \sigma$ acting as their "ligand" in a reverse signaling system similar to that found with Eph receptors (Mellitzer and Wilkinson, 2000). If so, then ectopic expression of $\mathrm{cPTP} \sigma$ ectodomains in the tectum may signal directly to retinal axons, perturbing their growth. To counter this model, our previous findings in tissue culture provided no suggestion that soluble ectodomains had a direct influence over retinal axons (Ledig et al., 1999a). Nevertheless, we cannot rule this out. In contrast, to potentially support the model, recent data from Drosophila indicate that the related RPTP, LAR, has a non-cell-autonomous role in photoreceptor axons (Maurel-Zaffran et al., 2001).

What is the nature of the tectal ligand for cPTP $\sigma$ ? We have demonstrated recently that HSPGs of the retinal basement membranes and glial end feet, present also in the optic tectum, represent a major class of high-affinity binding partner for $\mathrm{cPTP} \sigma$ (Aricescu et al., 2002). Therefore, it is most probable that our perturbation approach in ovo has interfered with these cРТР $\sigma$ / HSPG interactions, and this is now being tested further.

We found that abnormal axonal projections were often seen alongside axons that projected normally. This could reflect intrinsic differences between axons in their sensitivity to perturbation or variations in the efficiency of local ligand masking caused by the patchy expression characteristic of RCAS viruses. It is also possible, as with Drosophila RPTPs (Desai et al., 1997), that phenotypic penetrance is influenced by redundancy in RPTP function, because several vertebrate RPTPs are expressed in mosaic patterns in the retinal ganglion cell population (Fuchs et al., 1998; Ledig et al., 1999b; Johnson and Holt, 2000). It is worth considering the possibility that our perturbation approach has also affected RPTPs related to $\mathrm{cPTP} \sigma$, such as LAR and PTP $\delta$. These RPTPs are also expressed in retinal axons (Johnson et al., 2000), and they have the conserved HSPG-binding site seen in $\operatorname{cPTP} \sigma$ (Aricescu et al., 2002). Whether LAR and PTP $\delta$ bind these retinal and tectal HSPGs is currently not known.

If $\mathrm{cPTP} \sigma$ signals are to influence axonal behavior they must ultimately affect cytoskeletal dynamics. A relative of $\mathrm{cPTP} \sigma$, LAR, binds to Trio, a guanine exchange factor for Rho family
GTPases (Debant et al., 1996). Trio influences lamellipodial and filopodial dynamics in cells (Blangy et al., 2000), and Drosophila Trio synergizes with DLAR during CNS axon guidance (Bateman et al., 2000). cPTP $\sigma$ may also act through Trio because it binds to human Trio in yeast two-hybrid experiments (A. R. Aricescu and S. Schmidt, unpublished observations). The perturbation of $\operatorname{cPTP} \sigma$-ligand interactions in culture also causes a specific reduction in growth cone lamellipodia (Ledig et al., 1999a), structures controlled by rac activity. Defining whether cPTP $\sigma$ acts through such GTPases may be essential to explain the phenotypic influences that we have observed for this RPTP in retinal axons.

This study has demonstrated that interactions between the extracellular domains of axonal $\mathrm{cPTP} \sigma$ and their binding partners in the tectum are necessary both for sustained retinal axon growth over the optic tectum and for the correct topographic arborization of these axons. This provides the first demonstration of a function for a vertebrate RPTP during topographic targeting of axons in vivo. RPTP signaling can thus act in partnership with other growth and guidance systems of axons to control axon targeting in the brain.

\section{REFERENCES}

Ahmad F, Goldstein BJ (1997) Functional association between the insulin receptor and the transmembrane protein-tyrosine phosphatase LAR in intact cells. J Biol Chem 272:448-457.

Aicher B, Lerch MM, Muller T, Schilling J, Ullrich A (1997) Cellular redistribution of protein tyrosine phosphatases LAR and PTP $\sigma$ by inducible proteolytic processing. J Cell Biol 138:681-696.

Aricescu A, McKinnell I, Halfter W, Stoker AW (2002) Heparan sulphate proteoglycans are ligands for the receptor protein tyrosine phosphatase RPTPo. Mol Cell Biol 22:1881-1892.

Bateman J, Shu H, Van Vactor D (2000) The guanine nucleotide exchange factor trio mediates axonal development in the Drosophila embryo. Neuron 26:93-106.

Bell EJ, Brickell PM (1997) Replication-competent retroviral vectors for expressing genes in avian cells in vitro and in vivo. Mol Biotechnol 7:289-298.

Bilwes AM, Den Hertog J, Hunter T, Noel JP (1996) Structural basis for inhibition of receptor protein-tyrosine phosphatase- $\alpha$ by dimerization. Nature 382:555-559.

Bixby JL (2000) Receptor tyrosine phosphatases in axon growth and guidance. NeuroReport 11:5-10.

Blangy A, Vignal E, Schmidt S, Debant A, Gauthier-Rouviere C, Fort P (2000) TrioGEF1 controls Rac- and Cdc42-dependent cell structures through the direct activation of RhoG. J Cell Sci 113:729-739.

Burden-Gulley SM, Brady-Kalnay SM (1999) PTP $\mu$ regulates N-cadherin-dependent neurite outgrowth. J Cell Biol 144:1323-1336.

Chang S, Rathjen FG, Raper JA (1987) Extension of neurites on axons is impaired by antibodies against specific neural cell surface glycoproteins. J Cell Biol 104:355-362.

Chisholm A, Tessier-Lavigne M (1999) Conservation and divergence of axon guidance mechanisms. Curr Opin Neurobiol 9:603-615.

Cohen J, Burne JF, Winter J, Bartlett P (1986) Retinal ganglion cells lose response to laminin with maturation. Nature 322:465-467.

Debant A, Serra Pages C, Seipel K, O’Brien S, Tang M, Park SH, Streuli M (1996) The multidomain protein Trio binds the LAR transmembrane tyrosine phosphatase, contains a protein kinase domain, and has separate rac-specific and rho-specific guanine nucleotide exchange factor domains. Proc Natl Acad Sci USA 93:5466-5471.

Desai C, Krueger N, Saito H, Zinn K (1997) Competition and cooperation among receptor tyrosine phosphatases control motoneuron growth cone guidance in Drosophila. Development 124:1941-1952.

Desai DM, Sap J, Schlessinger J, Weiss A (1993) Ligand-mediated negative regulation of a chimeric transmembrane receptor tyrosine phosphatase. Cell 73:541-554.

Dingwell KS, Holt CE, Harris WA (2000) The multiple decisions made by growth cones of RGCs as they navigate from the retina to the tectum in Xenopus embryos. J Neurobiol 44:246-259.

Drescher U, Kremoser C, Handwerker C, Loschinger J, Noda M, Bonhoeffer F (1995) In vitro guidance of retinal ganglion cell axons by RAGS, a $25 \mathrm{kDa}$ tectal protein related to ligands for Eph receptor tyrosine kinases. Cell 82:359-370.

Drosopoulos NE, Walsh FS, Doherty P (1999) A soluble version of the receptor-like protein tyrosine phosphatase $\kappa$ stimulates neurite out- 
growth via a Grb2/MEK1-dependent signaling cascade. Mol Cell Neurosci 13:441-449.

Dütting D, Thanos S (1995) Early determination of nasal-temporal retinotopic specificity in the eye anlage of the chick embryo. Dev Biol 167:263-281.

Fekete DM, Cepko CL (1993) Replication-competent retroviral vectors encoding alkaline phosphatase reveal spatial restriction of viral gene expression/transduction in the chick embryo. Mol Cell Biol 13:2604-2613

Frisen J, Yates PA, McLaughlin T, Friedman GC, O'Leary DD, Barbacid M (1998) Ephrin-A5 (AL-1/RAGS) is essential for proper retinal axon guidance and topographic mapping in the mammalian visual system. Neuron 20:235-243.

Fuchs M, Wang H, Ciossek T, Chen Z, Ullrich A (1998) Differential expression of MAM-subfamily protein tyrosine phosphatases during mouse development. Mech Dev 70:91-109.

Garrity PA, Lee CH, Salecker I, Robertson HC, Desai CJ, Zinn K, Zipursky SL (1999) Retinal axon target selection in Drosophila is regulated by a receptor protein tyrosine phosphatase. Neuron 22:707-717.

Haj F, McKinnell I, Stoker A (1999) Retinotectal ligands for the receptor tyrosine phosphatase CRYP $\alpha$. Mol Cell Neurosci 14:225-240.

Hamburger V, Hamilton HL (1992) A series of normal stages in the development of the chick embryo (reprinted from 1951). Dev Dyn 195:231-272.

Honig MG, Hume RI (1986) Fluorescent carbocyanine dyes allow living neurons of identified origin to be studied in long-term cultures. J Cell Biol 103:171-187.

Hornberger MR, Dutting D, Ciossek T, Yamada T, Handwerker C, Lang S, Weth F, Huf J, Wessel R, Logan C, Tanaka H, Drescher U (1999) Modulation of EphA receptor function by coexpressed ephrinA ligands on retinal ganglion cell axons. Neuron 22:731-742.

Hughes SH, Greenhouse JJ, Petropoulos CJ, Sutrave P (1987) Adaptor plasmids simplify the insertion of foreign DNA into helperindependent retroviral vectors. J Virol 61:3004-3012.

Ichijo H (1999) Differentiation of the chick retinotectal topographic map by remodeling in specificity and refinement in accuracy. Brain Res Dev Brain Res 117:199-211.

Jiang G, den Hertog J Su J, Noel J, Sap J, Hunter T (1999) Dimerization inhibits the activity of receptor-like protein-tyrosine phosphatase- $\alpha$. Nature 401:606-610.

Johnson KG, Holt CE (2000) Expression of CRYP $\alpha$, LAR, PTP $\delta$, and PTP $\rho$ in the developing Xenopus visual system. Mech Dev 92:291-294. Johnson KG, McKinnell IW, Stoker AW, Holt CE (2001) Receptor protein tyrosine phosphatases regulate retinal ganglion cell axon outgrowth in the developing Xenopus visual system. J Neurobiol 49:99-117.

Kokel M, Borland CZ, DeLong L, Horvitz HR, Stern MJ (1998) clr-1 encodes a receptor tyrosine phosphatase that negatively regulates an FGF receptor signaling pathway in Caenorhabditis elegans. Genes Dev 12:1425-1437.

Kreis TE (1986) Microinjected antibodies against the cytoplasmic domain of vesicular stomatitis virus glycoprotein block its transport to the cell surface. EMBO J 5:931-941.

Ledig M, Haj F, McKinnell I, Stoker AW, Mueller B (1999a) The receptor tyrosine phosphatase $\mathrm{CRYP} \alpha$ promotes intraretinal axon growth. J Cell Biol 147:375-388.

Ledig MM, McKinnell IW, Mrsic-Flogel T, Wang J, Alvares C, Mason I, Bixby JL, Mueller BK, Stoker AW (1999b) Expression of receptor tyrosine phosphatases during development of the retinotectal projection of the chick. J Neurobiol 39:81-96.

Maurel-Zaffran C, Suzuki T, Gahmon G, Treisman JE, Dickson BJ (2001) Cell-autonomous and -nonautonomous functions of LAR in R7 photoreceptor axon targeting. Neuron 32:225-235.

McFarlane S, McNeill L, Holt CE (1995) FGF signaling and target recognition in the developing Xenopus visual system. Neuron 15:1017-1028.

Mellitzer G, Xu Q, Wilkinson DG (2000) Control of cell behaviour by signalling through Eph receptors and ephrins. Curr Opin Neurobiol 10:400-408.

Meng K, Rodriguez-Pena A, Dimitrov T, Chen W, Yamin M, Noda M, Deuel TF (2000) Pleiotrophin signals increased tyrosine phosphoryla- tion of $\beta$-catenin through inactivation of the intrinsic catalytic activity of the receptor-type protein tyrosine phosphatase $\beta / \zeta$. Proc Natl Acad Sci USA 97:2603-2608.

Monschau B, Kremoser C, Ohta K, Tanaka H, Kaneko T, Yamada T, Handwerker C, Hornberger MR, Loschinger J, Pasquale EB, Siever DA, Verderame MF, Muller BK, Bonhoeffer F, Drescher U (1997) Shared and distinct functions of RAGS and ELF-1 in guiding retinal axons. EMBO J 16:1258-1267.

Morgan BA, Fekete DM (1996) Manipulating gene expression with replication-competent retroviruses. Methods Cell Biol 51:185-218.

Muller BK, Jay DG, Bonhoeffer F (1996) Chromophore-assisted laser inactivation of a repulsive axonal guidance molecule. Curr Biol 6:1497-1502.

Nakamura H, O'Leary DD (1989) Inaccuracies in initial growth and arborization of chick retinotectal axons followed by course corrections and axon remodeling to develop topographic order. J Neurosci 9:3776-3795.

Neugebauer KM, Tomaselli KJ, Lilien J, Reichardt LF (1988) $\mathrm{N}$-cadherin, NCAM, and integrins promote retinal neurite outgrowth on astrocytes in vitro. J Cell Biol 107:1177-1187.

Newsome TP, Asling B, Dickson BJ (2000) Analysis of Drosophila photoreceptor axon guidance in eye-specific mosaics. Development 127:851-860.

O'Leary DD, Wilkinson DG (1999) Eph receptors and ephrins in neural development. Curr Opin Neurobiol 9:65-73.

Ostman A, Boehmer FD (2001) Regulation of receptor tyrosine kinase signaling by protein tyrosine phosphatases. Trends Genet 11:258-266.

Petrone A, Sap J (2000) Emerging issues in receptor protein tyrosine phosphatase function: lifting fog or simply shifting? J Cell Sci 113:2345-2354.

Schaapveld RQ, Schepens JT, Bachner D, Attema J, Wieringa B, Jpn PH, Hendriks WJ (1998) Developmental expression of the cell adhesion molecule-like protein tyrosine phosphatases LAR, RPTP $\delta$, and RPTP $\sigma$ in the mouse. Mech Dev 77:59-62.

SerraPages C, Saito H, Streuli M (1994) Mutational analysis of proprotein processing, subunit association, and shedding of the LAR transmembrane protein tyrosine phosphatase. J Biol Chem 269:23632-23641.

Stoker AW (1994) Isoforms of a novel cell adhesion molecule-like protein tyrosine phosphatase are implicated in neural development. Mech Dev 46:201-217.

Stoker AW (2001) Receptor tyrosine phosphatases in axon growth and guidance. Curr Opin Neurobiol 11:95-102.

Stoker AW, Gehrig B, Haj F, Bay BH (1995) Axonal localisation of the CAM-like tyrosine phosphatase CRYP $\alpha$ : a signalling molecule of embryonic growth cones. Development 121:1833-1844.

Suarez Pestana E, Tenev T, Gross S, Stoyanov B, Ogata M, Bohmer FD (1999) The transmembrane protein tyrosine phosphatase RPTP $\sigma$ modulates signaling of the epidermal growth factor receptor in A431 cells. Oncogene 18:4069-4079.

Sun QL, Wang J, Bookman RJ, Bixby JL (2000) Growth cone steering by receptor tyrosine phosphatase $\delta$ defines a distinct class of guidance cue. Mol Cell Neurosci 16:686-695.

Tessier Lavigne M, Goodman CS (1996) The molecular biology of axon guidance. Science 274:1123-1133.

Thanos S, Bonhoeffer F (1987) Axonal arborization in the developing chick retinotectal system. J Comp Neurol 261:155-164.

Thanos S, Mey J (2001) Development of the visual system of the chick. II. Mechanisms of axonal guidance. Brain Res Brain Res Rev 35:205-245

Thanos S, Bonhoeffer F, Rutishauser U (1984) Fiber-fiber interaction and tectal cues influence the development of the chicken retinotectal projection. Proc Natl Acad Sci USA 81:1906-1910.

Wang J, Bixby JL (1999) Receptor tyrosine phosphatase- $\delta$ is a homophilic, neurite-promoting cell adhesion molecule for CNS neurons. Mol Cell Neurosci 14:370-384.

Yates PA, Roskies AL, McLaughlin T, O'Leary DD (2001) Topographicspecific axon branching controlled by ephrin-As is the critical event in retinotectal map development. J Neurosci 21:8548-8563.

Yin X, Watanabe M, Rutishauser U (1995) Effect of polysialic acid on the behavior of retinal ganglion cell axons during growth into the optic tract and tectum. Development 121:3439-3446. 